\title{
NETWORK MUSICS - PLAY, ENGAGEMENT AND THE DEMOCRATIZATION OF PERFORMANCE
}

\author{
David Kim-Boyle \\ University of Maryland, \\ Baltimore County \\ Department of Music \\ 1000 Hilltop Circle, Baltimore, \\ MD 21250 \\ kimboyle@umbc.edu
}

\begin{abstract}
The rapid development of network communication technologies has allowed composers to create new ways in which to directly engage participants in the exploration of new musical environments. A number of distinctive aesthetic approaches to the musical application of networks will be outlined in this paper each of which is mediated and conditioned by the technical and aesthetic foundations of the network technologies themselves. Recent work in the field by artists such as Atau Tanaka and Metraform will be examined, as will some of the earlier pioneering work in the genre by Max Neuhaus. While recognizing the historical context of collaborative work, the author will examine how the strategies employed in the work of these artists have helped redefine a new aesthetics of engagement in which play, spatial and temporal dislocation are amongst the genre's defining characteristics.
\end{abstract}

\section{INTRODUCTION}

The development of high-speed network communication protocols and other wireless and telecommunications technology has allowed the creation of musical environments which directly engage participants in the realization of new forms of musical expression. These environments resituate the role of the composer to that of designer, often transforming the nature of performance to that of play. While the development of the genre has been informed by aesthetic concerns shared by all collaborative art, the spatial and, to some extent, temporal dislocation of participants conditions and mediates the nature of play itself to an unprecedented extent [1].

By actively engaging its audience, network-based musical environments recall the collaborative work of an earlier generation of composers such as Brown [3], Haubenstock-Ramati [10], Brün [4], Wolff [28], Pousseur [8], and Stockhausen [21] as well as the improvisatory work of groups such as AMM, Musica Electronica Viva and artists associated with the Fluxus School who directly situated the audience in performative roles. ${ }^{1}$ Much as the music of this earlier generation created unique opportunities for musical

\footnotetext{
${ }^{1}$ The term collaborative work will be used throughout in reference to any work in which performers or the audience are given creative responsibility for determining the order of musical events or, in some cases, for interpreting general musical processes. Open form and mobile form works are two examples of traditional collaborative work.
}

expression, composers working with networks, create environments which are musically expressed through playful exploration. The musical forms that emerge from these explorations and the relationships that develop between participants should be considered, however, in the context of the social goals that propelled the work of this earlier generation of composers.

Given the central aesthetic role the exploration of network-based musical environments plays, the extent to which the network's topology conditions the play of participants requires consideration [16]. While interactions between participants can occur over spatially distributed or localized environments, and the interactions and explorations themselves can be synchronous or asynchronous, the design of the interface through which these explorative behaviors are mediated is of equal importance. Informed by an understanding of the principles of game design theory, it will be argued that meaningful interaction and truly democratized performance spaces can only emerge from carefully considered system and interface design [19].

\section{MUSICAL APPROACHES}

While a number of studies have been published outlining different ways in which agents can collaborate with each other through a network infrastructure $[1,18$, $26,27]$, significantly less attention has been given to the different aesthetic approaches that these topologies facilitate. While the classification of network structures is helpful, the ways in which such structures condition the behavior of participants is equally significant. Some of the ways in which network topologies mediate musical expression will be explored in the remainder of this paper. Central to this discussion are the musical effects of spatial and temporal dislocation and the role of interface design.

A number of distinctive approaches to the musical application of networks can be seen to have emerged since the earliest experiments in the genre in the 1960s. These include the creation of network instruments, generative works, the integration of musical play within social networks and the creation of immersive environments.

\subsection{Network Instruments}

Amongst some of the earliest work to utilize telecommunication networks for artistic purposes are Max Neuhaus's radio projects. Between 1966 and 1977, 
Neuhaus produced a series of works, which he termed "Broadcast Works" in which the musical outcome is dependent upon the active responses of the audience. In the earliest of these works Public Supply I (1966), radio listeners were asked to call in to a radio station and produce any sounds they wanted. Neuhaus then mixed the incoming signals to produce the musical results. Neuhaus has written of these works - "...it seems that what these works are really about is proposing to reinstate a kind of music which we have forgotten about and which is perhaps the original impulse for music in man: not making a musical product to be listened to, but forming a dialogue, a dialogue without language, a sound dialogue." [16] The intention is strikingly similar to that expressed by Tanaka - "In classical art making, we have been mostly concerned with making objects nodes - is (sic.) time to think about the process of creating connections?" [22] and like much of Tanaka's network-based projects, Neuhaus's work exists as an environment which promotes the agency of its participants through the initiation and development of musical dialogs. In Public Supply I, however, Neuhaus mediates those relationships through the mixing process, reinforcing musically interesting dialogs while downplaying those of less appeal.

In a later realization of Neuhaus's project, listeners from across the Eastern United States were asked to call in and whistle a single pitch for as long as they were able. The work, entitled Radio Net, was produced in cooperation with National Public Radio. Unlike Public Supply I, in this work Neuhaus did not mix the responses live but rather, devised an automated mixing system in which the output switched between various input signals based on the pitch of the input sounds. The input whistles were also subject to electronic transformation as the sounds looped from one broadcast station to another. While Radio Net's realization was perhaps of more interest to its participants than a passive audience, and despite the fact that some thousands of listeners participated in the realization of the work, the result as realized in its only 1977 performance was coherent, subtle, and at times quite beautiful [14].

To the extent that Radio Net was developed as an environment within which musical dialogs could be formed and developed, the work does present a number of themes which we will see taken up in various forms in most subsequent network-based music. These include the role of the agency of others in conditioning one's own play, the degree to which dialogs are mediated by the mechanism's of the network, the public vs. private space of performance, the degree to which the dialogs enabled represent truly unique ways of communicating and the new role of the composer as a designer of a musical environment rather than a creator of selfcontained musical work. Rather than attempt to address the extent to which all these themes are addressed in Neuhaus's Broadcast Works, let us for now comment on the question of agency. The network infrastructure of Radio Net and the transformational processes employed would greatly inhibit the ability of participants to distinguish their own musical contribution much less be able to engage in meaningful dialog with others.
Nevertheless, through their participation, listeners were able to build a community brought together by the exploration of the network infrastructure. This would suggest that the goals of Radio Net were not so much the participation in dialog but rather the playful exploration of a network environment.

Like these earlier works, one of Neuhaus's most recent projects Auracle (2004) [15] adopts a similar network infrastructure although in this case the network no longer exists over radio transmissions but rather the internet. In Auracle, participants form ensembles and collectively modify an audio stream broadcast by a server through the use of their voice. In a similar manner to the Broadcast Works the resultant sounds of Auracle are affected by the proficiency of the participants but also by network latency. Network latency, a manifestation of temporal dislocation, is often considered a technical handicap for performers who wish to collaborate over the internet, but it is a key aesthetic consideration in the work of many composers who exploit it in the creation of unique musical environments. While latency is minimized in Auracle by the system architecture employed, it nevertheless clearly distinguishes the relationships participants form with the audio stream and through that with other ensemble members from those traditional relationships that exist between performers and their instruments.

Just as in the Broadcast Works Neuhaus regards Auracle not as a self-contained musical work in itself but as a collective instrument or musical architecture through which participants develop relationships through musical dialog. As implied above, those dialogs are necessarily mediated by the design of the instrument itself. The algorithm used to extract control features from the sonic input is not made explicit and the ability of participants to shape the audio stream with any degree of nuance is quite limited. Further, there is little direct indication as to how particular gestures modify the audio stream. While this would seem to inhibit the ability of participants to engage in meaningful dialog with other participants, it does reinforce the fact that like any instrument, Auracle has its own idiosyncrasies.

In comparison with the Broadcast Works, the use of an interface also represents an important distinction. Existing as the window through which the environment is explored and dialogs with ensemble members are developed, of immediate note is its simplicity. With the screen divided into discrete sections representing the geographical location of participants, the musical contributions of ensemble members is graphically represented by simple lines. Basic control functions allow participants to record brief audio samples which transform the audio stream. While control functions are simple they are a necessary consequence of the work's open environment. The interface design also enables ensemble members to more clearly distinguish their own musical contributions from those of other members. 


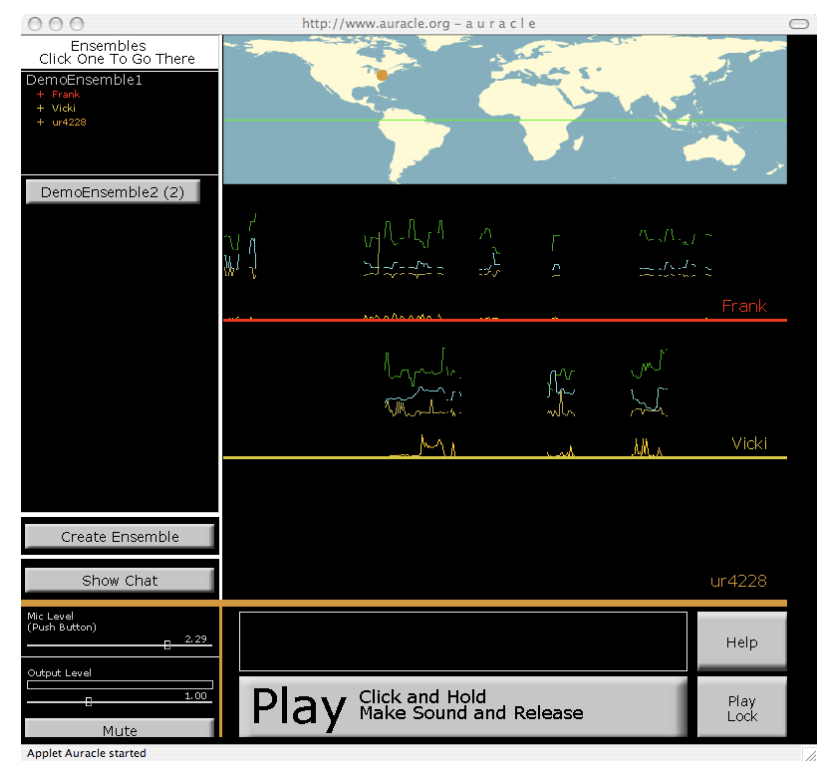

Figure 1. Interface for Max Neuhaus's Auracle.

Much of Atau Tanaka's work has employed networks to directly explore issues of collaboration and community building. In his Global String (1998), a project produced with Kasper Toeplitz, a network simulates an invisible resonant string whose nodes are anchored in different gallery installations. Tanaka writes of the project - "The installation consists of a real physical string connected to a virtual string on the network. The real string (12 mm diameter, $15 \mathrm{~m}$ length) stretches from the floor diagonally up to the ceiling of the installation space. On the floor is one end point the ear. Up above is the connection to the network, connecting it to another end point at a remote location. Sensors translate the vibrations into data to be transmitted to the other end via network protocol. The server is the "bridge" of the instrument - the reflecting point. It runs software that is a physical model of a string. Data is streamed back to each site as sound and as data - causing the string to become audible, and to be actuated to vibrate, on the other end." [24] Players of the string are able to collaborate with other players located in different installations in a topology similar to that of Weinberg's bridge model [27].

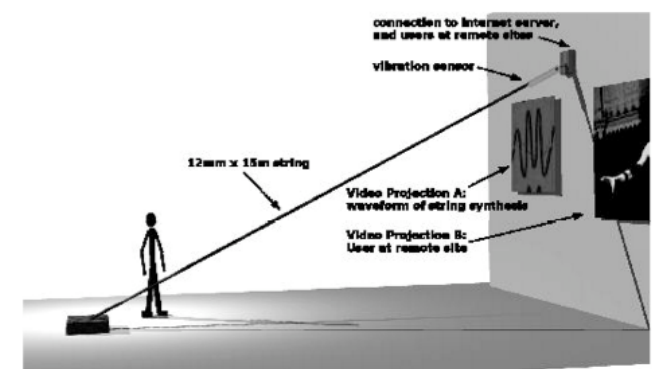

Figure 2. Installation setup for Tanaka's Global String.

Just like Neuhaus's Auracle, Global String is not a self-contained musical work but rather a network-based instrument that facilitates connections between participants across distributed space. In Global String, these connections are mediated by the latency of the network which Tanaka considers analogous to instrumental resonance [22], an idea also explored in the work of artists such as Carsten Nicolai and Ulrike Gabriel [2]. In Global String, network traffic between nodes is used to drive the parameters of the audio synthesis engine [2007, pers. comm. April], directly correlating temporal dislocation to musical expression. It thus makes explicit the ways in which the network mediates communication between participants making prominent the question of information transparency. Global String also is one of the few network instruments to incorporate haptic feedback within its infrastructure. This is an especially important design characteristic as, unlike software-based instruments, it more directly rewards performance skill and in doing so increases the likelihood of more meaningful play emerging [11].

\subsection{Generative Works}

The work of composer Jason Freeman, a collaborator with Neuhaus on Auracle, often addresses ways in which an audience can be engaged in the creation of unique musical forms. The design of carefully considered interfaces is crucial to this endeavor. Graph Theory is a recent web-based work in which participants do not directly interact with each other but rather help realize an open-form musical work by navigating pathways through a range of musical possibilities. In the work, basic melodic cells are repeatedly performed by a violinist. The user is able to choose which cell will follow the currently performed cell by choosing between up to four subsequent cells, see Fig. 3 top. There are a total of sixty one cells. While the order of cells is chosen by the participant, the range of possibilities is predetermined and displayed with a graphic representation of interconnected nodes. A novel aspect of this work is that a score can be generated for performance in which the order of the loops is determined by the popularity of choices made by users. While the content of the work is defined by the composer, the ability of a collective to determine its order is a unique feature and an extension of classic open-form works.

While the pathways chosen through the score are not overtly determined by the composer, they are certainly influenced by how the composer has decided to distribute musical phrases amongst nodal points. One of Freeman's pre-compositional rules was that adjacent cells could have only one change between their respective pitch sets. This decision introduced melodic continuity and helped keep decision making for the participants relatively simple. There were no such rules applied to rhythmic properties. The graphical representations employed were also considered in determining navigational pathways [2007, pers. comm. 2 January]. As participants navigating Graph Theory's structure do not interact with each other, questions of spatial distribution and temporal latency are not pertinent. The interface that Freeman has designed, however, does condition the play of those who interact 
with the materials broadcast by the server. A map of all possible pathways through the work's 61 nodes is presented in the bottom left quadrant of the interface. These pathways have a tri-partite structure which encourages both local exploration of neighboring nodes and implies greater musical contrast for larger crosssectional explorations. A participant's movement through the nodes of the work is also facilitated through the use of simple bar graphs for the display of rhythmic structure and pitch contour. This choice of display clearly renders the work more suitable to participants unable to read common practice notation.

Through immediate visual and aural feedback, participants of Graph Theory are clearly able to discern their actions and evaluate them in the context of previous and future decisions. They are also able to compare their choices with those of others through a simple "popularity" index which rates the frequency with which subsequent cells are chosen. The choices made are given a further complexity in that they contribute to a more global index used to create a score for live performance. Participants thus contribute to two distinct levels of performance - the private space performance that takes place within their own immediate interaction with the network, and the public space performance which results from the collective play of many participants.

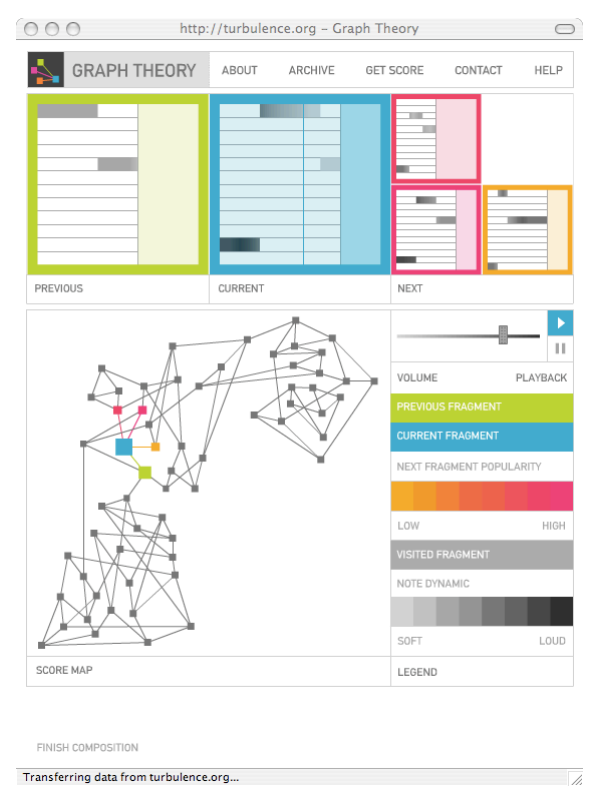

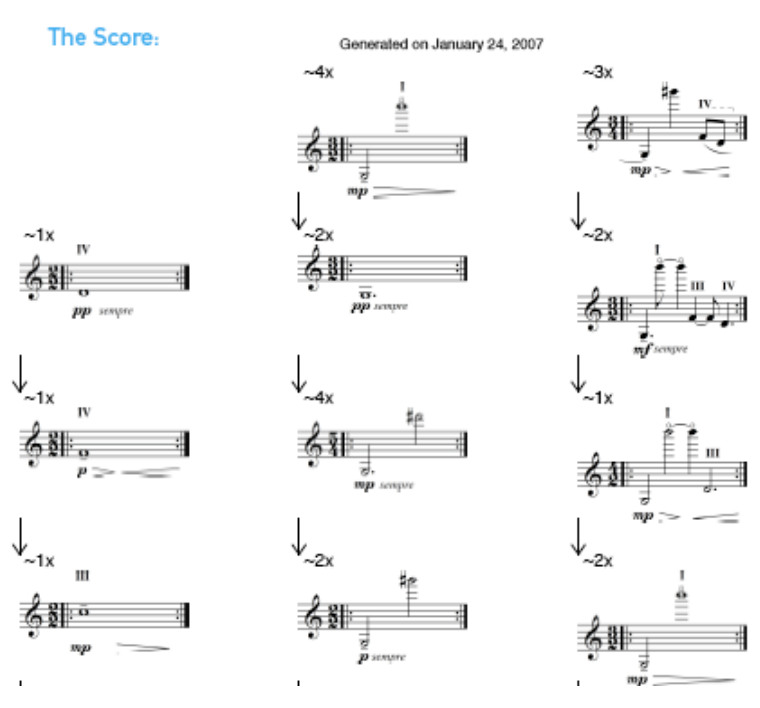

Figure 3. User interface for Graph Theory with an excerpt from the generated score.

\subsection{Social Networks}

In recent work, Atau Tanaka has utilized mobile network technology to build communities in which the members collaborate in shared musical experiences. His "Malleable Mobile Music" (2004) is a good example of this more recent direction. Using specially modified mobile communication devices equipped with physical sensors that measure both the pressure with which the device is held and its movement in space, participants are able to collectively remix a popular song chosen by the members of the network [23]. Various audio transformations such as time stretching and sampling can be applied, and rhythmic patterns and sequences can be generated from the original source material through various built-in software modules. Just as in open form works, these transformations can be applied in any order and the various contributions of each group member become an individual track in the master mix. The physical proximity of the participants which is determined through a GPS system is also used to affect the dynamic balance of the resultant mix directly correlating social proximity with musical presence. The results of the remixing and transformations are broadcast to all participants. More overtly than Neuhaus's Auracle, Tanaka's instrument creates immediate collaborative relationships and communities through the virtual environment of the network technology employed. The "Malleable Mobile Music" project has recently been employed in a new interactive work, Net_Dérive, for mobile, wearable communication devices. This latter project was produced in collaboration with Petra Gemeinboeck and received its premiere in Paris in 2006 [25]. 


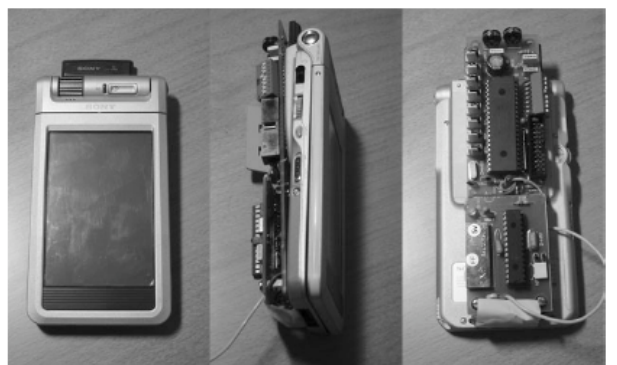

Figure 4. Specially modified PDAs for Malleable Mobile Music.

\subsection{Immersive Works}

A different type of musical collaboration is explored in immersive works [7]. In Ecstasis by the Australian ensemble Metraform, four participants engage in exploring and decoding a virtual environment through the use of head-mounted displays equipped with motion tracking devices. The images seen through the displays are also projected on four screens surrounding the participants. In Ecstasis, the participants, each graphically represented by an avatar, determine the nature and scope of the work through their interactions. Metraform has written of Ecstasis - "The relationship between the avatars modulates the space, colour, transparency and sound of the environment. The collective interaction results in a dynamic interplay with and within a continuously modifiable environment. This engagement transgresses from a preoccupation of 'doing' something in an environment to 'being' present to one's self and others." [13]

In Ecstasis and other recent work by the ensemble, sound is employed as a means of environmental understanding. The soundscape of the work was produced by composer Lawrence Harvey. The sounds heard, and the sound transformations applied are determined by the virtual location of each of the four participants as well as from information derived from the motion of the head-mounted displays. Consisting of sixteen channels of spatialized sound, the sounds complement the images generated and provide easily discerned sonic cues that help establish cooperative relationships between the participants. Ecstasis defines clear goals for its participants and rewards their explorations with a greater understanding of their environment. Through the environmental space that the work presents, Ecstasis becomes a catalyst for collective individuation [12]. As its participants decode their environment and come to a greater collective awareness it is clear that the disjunctions between interface and environment and public and private performance spaces are no longer sustainable.

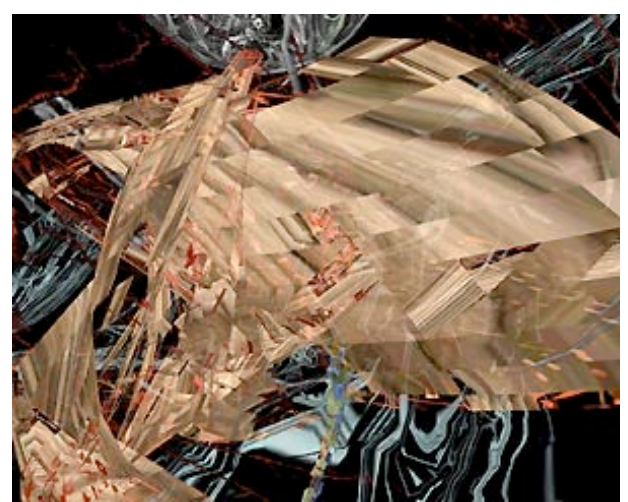

Figure 5. A screenshot from Ecstasis.

\section{AESTHETIC THEMES}

While each network project examined posits its own aesthetic questions, they all share a number of common concerns. These range from questions regarding the democratized performance space which network-based work promotes, through to questions provoked by the technology through which these works are sustained. Some of these questions include consideration of how the spatial and temporal aesthetics of network technologies mediate collaborative relationships [11] while others make overt the influence of interface design in the promotion of democratized performance environments.

Given the creative role participants play in exploring their musical environments, the role of the composer has largely become transformed to that of designer while the traditional role of the performer has been subsumed by that of player. To a certain extent this situation is paralleled in traditional open-form works in which composers design open musical environments which serve to facilitate an awareness of process and collective becoming. All network-based musical works posit environments within which relationships between participants are facilitated and developed. The directives which determine the extent to which these environments can be explored and relationships developed differs from composer to composer and from project to project. While artists such as Tanaka and Neuhaus encourage collaborative relationships and dialogs to be openly explored within the boundaries of their environments, other artists such as Metraform, and Freeman adopt a less open approach and predefine particular social goals through and for their work. In Metraform's Ecstasis, as we have seen, this took the form of an improved environmental understanding while the creation of a performable work was an explicit goal of Freeman's Graph Theory. Given the responsibility assumed of participants, the composer or designer of that environment must also assume some responsibility for the quality of those relationships that emerge. Dobrian goes further and states that in a collective performance it is up to the composer to develop an environment within which compelling work can take place [9] while Tanaka has stated that interesting results can only be achieved by developing interesting processes [2007, pers. comm. April]. Bryan-Kinns and Healey have even shown that 
the effect of decay within a collective instrument significantly affects how participants engage with that environment [5]. As we have seen in the work of Neuhaus and Freeman, interface design is of critical importance in conditioning the ways in which processes, environments and relationships are able to be explored while in Tanaka's Global String, haptic feedback is a critical component in the development of meaningful play. Indeed, as has become evident, democratized performance spaces can only be realized through carefully considered interface design.

Transparent interface design also facilitates the ability of participants to surrender to their environment rather than have to decode the means through which it is presented. How that environment responds to their own agency is of especial importance. As noted by Phillips and Rabinowitz,

...when the audience expects instant response, asks the piece for self-affirmation or affirmation of a learned behavior, the effect closes down what the piece means to open up. Collaborative art asks for something as complex as inspired surrender and must elicit recognition, building from reflection. That moment of self-regard should then develop into more complicated correspondences. Otherwise, the piece can veer toward superficiality and rely on what we call a "supermarket door process of interactivity": I walked up to it and it opened' I have power [17].

While technology has not fundamentally changed the defining characteristics of collaborative art forms, it has certainly mediated them in distinctive ways. In some environments, such as in Metraform's Ecstasis, this has brought about unique modes of engagement while in other projects network latency has produced collective instruments the aesthetics of which are founded on immediacy and extended reflection [24]. Of defining character, of course, are the spatial and temporal properties of the network infrastructure or topology. While these are able to be exploited to musical effect, it is perhaps counterintuitive that spatial disjunction and temporal dislocation can also perhaps serve to facilitate a greater awareness of agency and collective becoming.

\section{SUMMARY}

The democratized performance spaces that network-based musical environments supports are a natural response to the musical and social ideals that motivated the work of an earlier generation of composers for whom such technology did not exist. These technologies have brought about new modes of awareness of individual agency and of the creative relationships that can emerge with others through the playful exploration of the architectures that sustain musical collaboration. The aesthetic features unique to the genre emphasize the challenges of fully engaging participants in collaborative processes and moving participants beyond the easy solution of falling back on what Cage has referred to as superficial habits [6]. These challenges are amply rewarded, however, by the exciting potential of network music to create unique forms of musical expression and new modes of musical agency and engagement and in doing so to transcend the network architectures that make such dialogs and relationships possible.

\section{ACKNOWLEDGMENTS}

I am grateful to Jason Freeman, Lawrence Harvey and Atau Tanaka for providing further information on their work. I would also like to thank John Dack for generously providing a copy of his article on the Scambi project.

\section{REFERENCES}

[1] Barbosa, A. "Displaced soundscapes: a survey of network systems for music and sonic art creation", Leonardo Music Journal, vol. 13, 2003, 53-59.

[2] Broeckmann, A. "Reseau/Resonance - connective processes and artistic practice", Artmedia VIII, 2002, Viewed March 2007,

$<\mathrm{http}$ ://www.olats.org/projetpart/artmedia/2002eng/t e_aBroeckmann.html $>$.

[3] Brown, E. "Form in new music", Darmstadter Beitrager, vol. 10, 1965, 57-69.

[4] Brün, H. When music resists meaning: the major writings of Herbert Brün. Ed. A Chandra, Wesleyan University Press, Middletown, CN, 2004.

[5] Bryan-Kinns, N. and Healey, P.G.T. "Decay in collaborative music making", Proceedings of the 2006 International Conference on New Interfaces for Musical Expression (NIME06), Paris, 2006, 114117.

[6] Cage, J. Soundings: investigation into the nature of modern music. Neuberger.

[7] Chew, E, Kyriakakis, C., Papadopoulos, C., Sawchuk, A. A., and Zimmermann, R. "From remote media immersion to distributed immersive performance", Proceedings of the 2003 ACM SIGMM Workshop on Experiential Telepresence, Berkeley, CA, 2003, 110-120.

[8] Dack, J. ““'Open” forms and the computer", In Musiques, Arts, Technologies: Towards a Critical Approach. L'Harmattan, Paris, 2004, 401-412.

[9] Dobrian, C. "Aesthetic considerations in the use of "virtual" music instruments", Proceedings of the 2003 International Conference on New Interfaces for Musical Expression (NIME03), Montreal, 2003, 161-163.

[10] Haubenstock-Ramati, R. "Notation - material and form”, Perspectives of New Music, Vol. 4, No. 1, 1965, 39-44.

[11] Leman, M. Embodied music cognition and mediation technology. MIT Press, Cambridge, MA, 2007.

[12] Massumi, B. "The Political Economy of Belonging”, In Parables for the Virtual: Movement, 
Affect, Sensation. Duke University Press, Durham, NC, 2002.

[13] Metraform. Ecstasis. 2004, Viewed December 2006, $<$ http://www.metraform.com>.

[14] Neuhaus, M. Radio Net. 1977. Available at $<\mathrm{http}$ ://www.ubu.com/sound/neuhaus_radio.html $>$.

[15] Neuhaus, M., Freeman, J., Ramakrishnan, C., Varnick, K., Burk, P., and Birchfield, D. Auracle. 2006, Viewed June 2006, <http://auracle.org>.

[16] Neuhaus, M. The broadcast works and Audium. 2007, Viewed January 2007, <http://www.maxneuhaus.info $>$.

[17] Phillips, L., and Rabinowitz, P. "On collaborating with an audience", Collaborative Journal, 2006, Viewed January 2006,

$<$ http://www.artcircles.org/id85.html $>$.

[18] Rebelo, P. "Network performance: strategies and applications", Presentation at the 2006 International Conference on New Interfaces for Musical Expression (NIME06), Paris, 2006, Viewed March 2007, <http://www.sarc.qub.ac.uk/ prebelo/index>

[19] Salen, K., and Zimmerman, E. Rules of Play: Game Design Fundamentals. MIT Press, Cambridge, MA, 2004.

[20] Souza e Silva, A. "Art by telephone: from static to mobile interfaces", Leonardo Electronic Almanac, vol. 12, no. 10, 2004.

[21] Stockhausen, K. “...how time passes....", Trans. C Cardew, Die Reihe, 3 (1959), Bryn Mawr, PA, 1040.

[22] Tanaka, A. "Seeking interaction, changing space", Proceedings of the 6th International Art + Communication Festival 2003, Riga, Latvia, 2003, Viewed July 2006, $<$ http://www.csl.sony.fr/ atau/>.

[23] Tanaka, A. "Mobile music making", Proceedings of New Interfaces for Musical Expression 2004 Conference, Hamamatsu, 2004, 154-156.

[24] Tanaka, A. Global String. 2005, Viewed July 2006, $<$ www.sensorband.com/atau/globalstring/globalstrin g.pdf>.

[25] Tanaka, A., Gemeinboeck, P., and Momeni, A. "Net_Dérive, a participative artwork for mobile media", In-press, 2007.

[26] Turbulence.org. Viewed January 2006, $<$ http://www.turbulence.org $>$.

[27] Weinberg, G. "Interconnected musical networks: toward a theoretical framework", Computer Music Journal, 29:2, 23-39.

[28] Wolff, C. "Open to whom and to what", Interface, $16 / 3,1987,133-141$. 